\title{
Comparison of ECV measurements during equilibrium between IR- and SR-based Cardiac T Mapping
}

\author{
Kyungpyo Hong ${ }^{*}$, Eugene G Kholmovski ${ }^{1}$, Christopher J McGann², Ravi Ranjan², Daniel Kim ${ }^{1}$ \\ From 17th Annual SCMR Scientific Sessions \\ New Orleans, LA, USA. 16-19 January 2014
}

\section{Background}

Cardiac $\mathrm{T}_{1}$ and extracellular volume fraction (ECV), derived from pre- and post-contrast cardiac and blood $\mathrm{T}_{1}$ measurements, are emerging imaging biomarkers of diffuse cardiac fibrosis. The most frequently used cardiac $\mathrm{T}_{1}$ mapping pulse sequence is MOLLI [1]. However, MOLLI is known to be sensitive to rapid heart rate and irregular rhythm, because it is based on inversion-recovery (IR) of magnetization preparation. In response, we developed an arrhythmia-insensitive-rapid (AIR) cardiac T1 mapping pulse sequence based on $\mathrm{B}_{1}$ insensitive saturation-recovery (SR) of magnetization preparation [2]. Our prior study [2] showed that AIR (scan time $=2-3$ heart beats) is faster and yields more accurate cardiac $\mathrm{T}_{1}$ measurements than MOLLI (scan time $=17$ heart beats). We sought to compare ECV measurements between SR-based AIR and IR-based MOLLI cardiac $\mathrm{T}_{1}$ mapping at $3 \mathrm{~T}$.

\section{Methods}

Sixteen mongrel dogs with normal myocardium were imaged at 3T (Verio, Siemens). Cardiac $\mathrm{T}_{1}$ maps were acquired in a mid-ventricular short-axis plane using both AIR and MOLLI cardiac $T_{1}$ mapping at baseline and during equilibrium of Gd-BOPTA (Multihance; $30 \mathrm{~min}$ after slow infusion at $0.002 \mathrm{mmol} / \mathrm{kg} / \mathrm{min})$. Note that equilibrium ensures identical concentration of Gd-BOPTA for a fair comparison of cardiac and blood $T_{1}$ measured by two different pulse sequences. Both AIR and MOLLI acquisitions with b-SSFP readout were performed with the following relevant imaging parameters: spatial resolu- tion $=1.4 \times 1.4 \times 7.0 \mathrm{~mm}$, temporal resolution $=217 \mathrm{~ms}$, flip angle $=35^{\circ}$, and SR time $=600 \mathrm{~ms}$. The AIR acquisition was performed with "paired" consecutive phaseencoding steps in centric k-space ordering to minimize image artifacts due to eddy currents. Blood samples were drawn during MRI for hematocrit calculation. AIR and MOLLI cardiac $\mathrm{T}_{1}$ maps were manually segmented to calculate the myocardial and blood $\mathrm{T}_{1}$ values and subsequently $E C V=(1$-hematocrit $) x\left(\Delta R_{1}\right.$, myocardium $/ \Delta R_{1}$, blood $)$, where $R_{1}$ is $T_{1}{ }^{-1}$, and $\Delta$ is the difference between postand pre-contrast. Paired-wise t-test and Bland-Altman analyses were performed to compare the results.

\section{Results}

Figure 1 shows representative AIR and MOLLI cardiac $\mathrm{T}_{1}$ maps which exhibit similarly high image quality. In the 16 dogs studied (mean heart rate $=100 \pm 19 \mathrm{BPM}$ ), compared with MOLLI, AIR yielded higher $\mathrm{T}_{1}$ measurements $($ mean difference $=185 \mathrm{~ms} ; \mathrm{p}<0.0001)$ and lower ECV measurements (mean difference $=-0.018$; $\mathrm{p}<0.0001)$.

\section{Conclusions}

Our study suggests that MOLLI and AIR cardiac $\mathrm{T}_{1}$ mapping pulse sequences yield significantly different $T_{1}$ and ECV measurements. ECV measurements derived from SR-based AIR and IR-based MOLLI cardiac $\mathrm{T}_{1}$ mapping pulse sequences may need to be adjusted for comparison

\section{Funding}

Ben B. and Iris M. Margolis Foundation. 


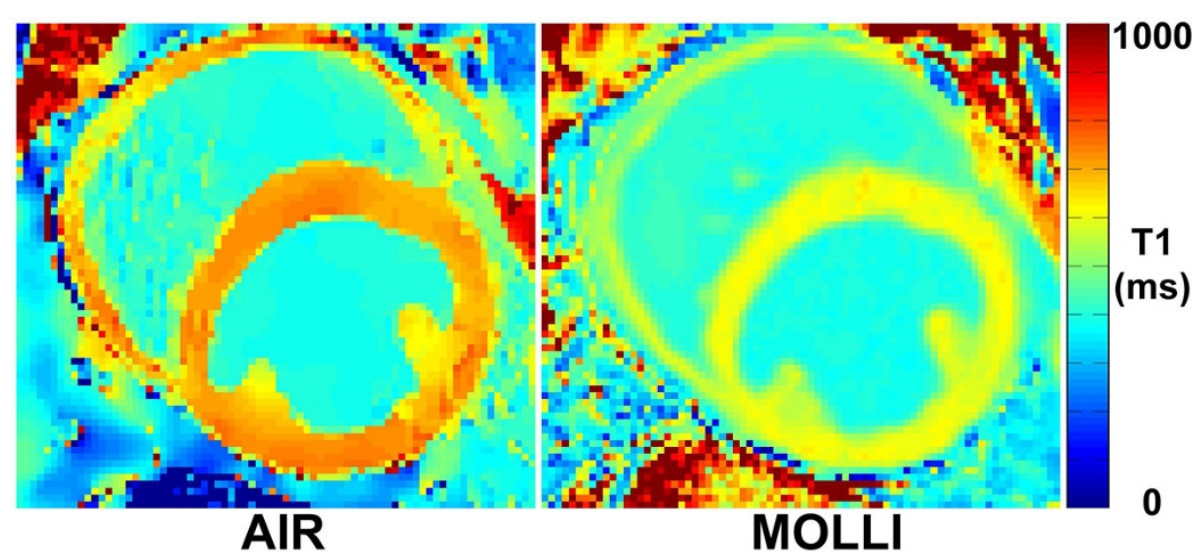

Figure 1 Example SR-based AIR and IR-based MOLLI cardiac $T_{1}$ maps of the same animal acquired during equilibrium.
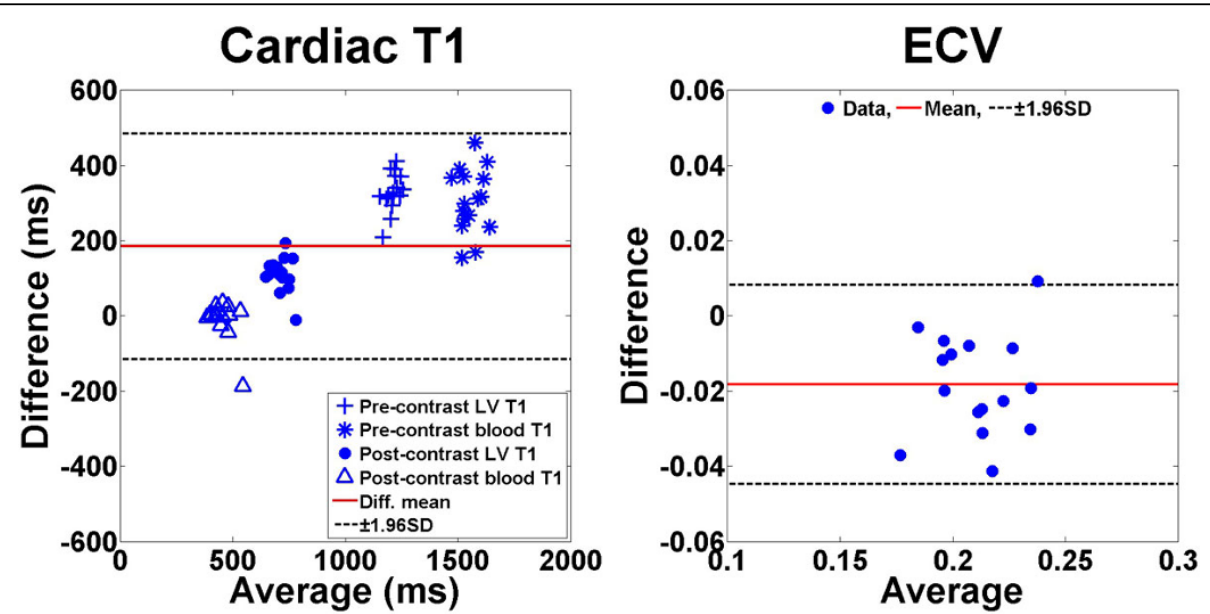

Figure 2 Bland-Altman plots comparing (left) cardiac $T_{1}$ and (right) ECV measurements derived from SR-based AIR and IR-based MOLLI cardiac $\mathrm{T}_{1}$ mapping.

\section{Authors' details}

${ }^{1}$ UCAIR, Radiology, University of Utah, Salt Lake City, Utah, USA. ${ }^{2}$ Division of

Cardiology, Internal Medicine, University of Utah, Salt Lake City, Utah, USA.

Published: 16 January 2014

\section{References}

1. Messroghli DR, et al: MRM 2004, 141-146.

2. Fitts $M$, et al: MRM 2012, DOl:10.1002/mrm.24586.

doi:10.1186/1532-429X-16-S1-P53

Cite this article as: Hong et al:: Comparison of ECV measurements during equilibrium between IR- and SR-based Cardiac T Mapping. Journal of Cardiovascular Magnetic Resonance 2014 16(Suppl 1):P53.
Submit your next manuscript to BioMed Central and take full advantage of:

- Convenient online submission

- Thorough peer review

- No space constraints or color figure charges

- Immediate publication on acceptance

- Inclusion in PubMed, CAS, Scopus and Google Scholar

- Research which is freely available for redistribution 